\title{
Association of diabetes and cancer mortality in American Indians: the Strong Heart Study
}

\author{
Lyle G. Best ${ }^{1,11} \cdot$ Esther García-Esquinas $^{2,3,4} \cdot$ Jeun-Liang Yeh $^{5} \cdot$ Fawn Yeh $^{5}$. \\ Ying Zhang ${ }^{5}$ Elisa T. Lee ${ }^{5}$ Barbara V. Howard ${ }^{6,7} \cdot$ John H. Farley $^{8}$. \\ Thomas K. Welty ${ }^{1} \cdot$ Dorothy A. Rhoades $^{9} \cdot$ Everett R. Rhoades $^{5} \cdot$ Jason G. Umans $^{6}$. \\ Ana Navas-Acien ${ }^{2,10}$
}

Received: 3 January 2015/Accepted: 29 July 2015/Published online: 7 August 2015

(C) The Author(s) 2015

\begin{abstract}
Purpose The metabolic abnormalities that accompany diabetes mellitus are associated with an increased risk of many cancers. These associations, however, have not been well studied in American Indian populations, which experience a high prevalence of diabetes. The Strong Heart Study is a population-based, prospective cohort study with extensive characterization of diabetes status.

Methods Among a total cohort of 4,419 participants who were followed for up to 20 years, 430 cancer deaths were identified. Results After adjusting for sex, age, education, smoking status, drinking status, and body mass index, participants with diabetes at baseline showed an increased risk of gastric (HR 4.09; $95 \%$ CI 1.42-11.79), hepatocellular (HR 2.94; $95 \%$ CI 1.17-7.40), and prostate cancer mortality (HR 3.10; $95 \%$ CI 1.22-7.94). Further adjustment for arsenic exposure showed a significantly increased risk of all-cause cancer mortality with diabetes (HR 1.27; $95 \%$ CI 1.03-1.58). Insulin resistance among participants without diabetes at baseline was associated
\end{abstract}

Lyle G. Best

lbest@restel.com

$1 \quad$ Epidemiology Department, Missouri Breaks Industries Research Inc., 118 S. Willow Str, Timber Lake 57625, SD, USA

2 Department of Environmental Health Sciences, Johns Hopkins University Bloomberg School of Public Health, Baltimore, MD, USA

3 Department of Preventive Medicine and Public Health, Universidad Autónoma de Madrid, Madrid, Spain

4 CIBERESP, Madrid, Spain

5 Center for American Indian Health Research, College of Public Health, University of Oklahoma Health Sciences Center, Oklahoma City, OK, USA with hepatocellular cancer mortality (HR 4.70; $95 \%$ CI 1.55-14.26).

Conclusions Diabetes mellitus, and/or insulin resistance among those without diabetes, is a risk factor for gastric, hepatocellular, and prostate cancer in these American Indian communities, although relatively small sample size suggests cautious interpretation. Additional research is needed to evaluate the role of diabetes and obesity on cancer incidence in American Indian communities as well as the importance of diabetes prevention and control in reducing the burden of cancer incidence and mortality in the study population.

Keywords Diabetes mellitus - Cancer · American Indian

\section{Introduction}

A growing body of evidence links diabetes and chronic hyperglycemia with the development of several common cancers, including pancreas, liver, colon, and breast

6 MedStar Health Research Institute, Hyattsville, MD, USA

7 Georgetown-Howard Universities Center for Clinical and Translational Science, Washington, DC, USA

8 Division of Gynecology Oncology, Department of Obstetrics and Gynecology, Creighton University School of Medicine at St. Joseph's Hospital and Medical Center, Phoenix, AZ, USA

9 Stephenson Cancer Center and Department of Medicine, University of Oklahoma Health Sciences Center, Oklahoma City, OK, USA

10 Department of Oncology, Johns Hopkins School of Medicine, Baltimore, MD, USA

111935 118th Ave NW, Watford City, ND 58854, USA 
cancers [1-5]. In a meta-analysis of 12 studies from Europe, Asia, and the USA, diabetes was also associated with increased all-cause cancer mortality (pooled relative risk $1.16,95 \%$ CI 1.03-1.30) [6].

Biologic plausibility for a direct causal association between cancer and hyperglycemia was first suggested in the early 1900s by Warburg et al. based on the increased reliance of cancer cells on glucose and aerobic glycolysis (the "Warburg Effect") [7]. This effect has recently been further corroborated by the detection of increased glucose metabolism in malignant tissue [8] and the demonstration of these metabolic changes in individual cancer cells [9]. The increased availability of glucose may enhance the survival of malignant cells in their early stages or provide a growth advantage during later stages. Insulin, and insulin-like growth factors (IGFs) which are increased during much of the course of type II diabetes [10, 11 ], could also increase cancer risk.

Cancer has become a leading cause of death among American Indians [12, 13], who have the highest rates of type 2 diabetes in the USA [14-16]. Little is known, however, about the associations between hyperglycemic conditions and cancer among American Indians. In 2003, the Strong Heart Study, a population-based prospective cohort study in American Indian communities of Arizona, Oklahoma, and North and South Dakota, failed to identify an association between diabetes and all-cause cancer mortality over 9 years of follow-up [17]. However, that initial study was limited by a small number of cases of cancer mortality as well as a relatively short period of follow-up. In addition, specific cancers were not evaluated in that report [17].

The Strong Heart Study has continued to follow older American Indians since 1989, contributing important information on the relationship of diabetes and hyperglycemic conditions to complex diseases [18-21]. Although the study was primarily funded to investigate cardiovascular disease and its risk factors, cancer deaths have also been identified as part of the mortality surveillance system. The objective of the current study is to determine the association of diabetes, hyperglycemia, and insulin resistance with cancer mortality among American Indians participating in the Strong Heart Study. Based on the evidence from other populations, we hypothesized that diabetes would be associated with an increase in total cancer mortality, as well as with the following cancer-specific mortalities: gastric, colorectal, breast, renal cell, liver, and pancreas cancer.

\section{Methods}

\section{Study population}

From 1989 to 1991 , men and women 45-75 years of age from 13 American Indian communities were invited to participate in the Strong Heart Study. In Arizona and Oklahoma, every eligible person was invited, whereas in North/South Dakota, a cluster sampling technique was used. The baseline participation rate was $62 \%$, with a final sample of 4,549 participants. All analysis was based on baseline data collected in the first examination of this cohort in 1989-1991. For this study, we excluded participants missing information on diabetes status $(n=90)$, body mass index (BMI) $(n=20)$, smoking status $(n=8)$, alcohol consumption $(n=8)$, and education level $(n=4)$, leaving 4,419 participants for analysis. The SHS protocol was approved by multiple institutional review boards and by the participating communities. All participants provided oral and written informed consent.

\section{Data collection}

Study visits were performed by trained and certified examiners following a standard protocol and included a questionnaire (sociodemographic factors, environmental exposures, and medical history), a physical examination (height, weight, and blood pressure), and bio-specimen collection (blood, urine). Participants were asked to fast for $12 \mathrm{~h}$ before blood collection. Plasma glucose was measured by a hexokinase method at MedStar Health Research Institute (MHRI), Hyattsville, MD. A 2-h, 75-g oral glucose tolerance test was performed in participants without diabetes medication. The oral glucose tolerance test was not performed if the participant received renal dialysis (or a renal transplant) or if the fasting glucose level was greater than $225 \mathrm{mg} / \mathrm{dL}$ as determined by Acucek II (Baxter Healthcare, Grand Prairie, Texas). HbA1c was measured by a high-performance liquid chromatography method at the laboratory of the National Institute of Diabetes and Digestive and Kidney Diseases Epidemiology and Clinical Research Branch, Phoenix, Arizona. Plasma insulin was measured at MHRI by radioimmunoassay (Linco, St. Louis, Missouri).

\section{Diabetes definition}

Diabetes was defined as a fasting glucose level $\geq 126 \mathrm{mg} /$ $\mathrm{dL}$ or the use of insulin or oral hypoglycemic medication. Those on renal dialysis or with a kidney transplant and that responded positively to the question "Has a medical person ever told you that you had diabetes?" were also classified as having diabetes. The date of diagnosis was either the date of the baseline examination resulting in diagnostic criteria or the self-reported date of diagnosis from the baseline questionnaire. Because type 1 diabetes is rare, we assumed essentially all cases in our study have type 2 diabetes. Impaired fasting glucose (IFG) was defined as fasting glucose $\geq 100$ and $<126 \mathrm{mg} / \mathrm{dL}$ in the absence of 
diabetes as defined above. Insulin resistance was estimated in non-diabetic participants using the homeostasis model assessment to quantify insulin resistance (HOMA$\mathrm{IR})=[$ fasting plasma insulin $(\mathrm{mU} / \mathrm{L}) \times$ fasting plasma glucose (mmol/L)]/22.5. In addition to HOMA-IR, we also evaluated plasma insulin.

\section{Cancer mortality follow-up}

Follow-up for mortality was complete for $99.8 \%$ of the study population. Death certificates were obtained from the State Departments of Health and the underlying cause of death used in analysis. If the death certificate indicated that an autopsy had been performed, the medical examiner's report was obtained. Death certificate codes were recorded according to the International Classification of Diseases, 9th Revision (ICD-9). In addition to overall cancer, we evaluated the following specific cancers: esophagus and stomach (ICD-9 150-151), colon and rectum (153-154), liver and intrahepatic bile ducts (157) (referred to from now on as liver cancer), gallbladder and extrahepatic bile ducts (156), bronchus and lung (162.2-162.9), breast (174), prostate (185), kidney (189.0), and lymphatic and hematopoietic tissue (200-208). The follow-up interval was calculated from the date of baseline examination to the date of death or 31 December 2008, whichever occurred first. The median follow-up time among participants who did not develop cancer was 17.2 years.

We conducted and have presented the analyses for all cancers, except for those which had too few deaths to properly analyze (brain, skin, and reproductive organs). Analyses for HbA1c and HOMA-IR are only shown for cancers that we found a statistically significant association with diabetes or a suggestive trend for a cancer previously associated with diabetes such as colorectal cancer. For the other cancers, we confirmed that none of them was associated with HbA1c or HOMA-IR (data not shown).

\section{Statistical methods}

Statistical analyses were conducted with Stata version 12.1 (StataCorp LP, College Station, Texas). The figures were conducted with $\mathrm{R}$ version 3.0.1 ( $\mathrm{R}$ project for statistical computing). The prospective association between baseline diabetes status (as a dichotomous trait, as well as a categorical trait (i.e., no IFG, IFG, or diabetes)) and cancer mortality (overall and site specific) was assessed using Cox proportional hazards models with age as timescale and individual starting follow-up times treated as staggered entries. The nonparametric underlying baseline hazards were allowed to differ by study region using the strata option. By adding study region as strata, the model adjusts for region, but no association is estimated for region and region does not need to meet the assumption of proportionality of hazards. Initial Cox proportional hazards models accounted for age, sex, and region (model 1). Model 2 also adjusted for BMI, and in the case of breast cancer for baseline menopausal status (pre/post), hormone replacement therapy (current/past/never use), and parity ( $0 /$ $1-2 / 3-4 / \geq 5$ ). Model 3 further adjusted for education, smoking (never, former, current), and drinking status (never drinker, former drinker, light current drinker $(<4$ drinks/week), moderate current drinkers (4-12 drinks/ week), heavy drinkers ( $>12$ drinks/week)) [22]. The assumption of hazards proportionality was evaluated visually based on the smoothed association between age and scaled Schoenfeld residuals, with no major departures from proportionality.

To evaluate the relationship between HbA1c and cancer mortality, we modeled $\mathrm{HbA} 1 \mathrm{c}$ as a continuous variable and derived adjusted hazard ratios of cancer mortality comparing the 80th versus the 20th percentiles of HbA1c. Additionally, HbA1c levels were separately modeled using restricted cubic splines with knots at the 10th (4.6\%), 50th $(5.6 \%)$, and 90th $(10.7 \%)$ percentile of its distribution.

HOMA-IR values were log-transformed, and their association with cancer mortality was evaluated using Cox proportional hazards models, using the same levels of adjustment as in models 1-3 but restricted to participants without diabetes. Plasma insulin was also log-transformed and analyzed similarly in a separate model.

Subgroup analyses (e.g., by sex, age groups, or smoking status) were not performed due to limited sample size, especially for specific cancer types. We performed several sensitivity analyses. First, we further adjusted for cigarette pack-years as well as for arsenic in the subset of participants with information on pack-years and urine arsenic concentrations available $(n=3,737)$. Arsenic is an established carcinogen that has been related to cancer mortality [23] and diabetes [24] in the Strong Heart Study. Second, we further adjusted for time since the diagnosis of diabetes. Third, to account for competing risks by causes of death other than cancer, we estimated proportional hazards regression models according to the method of Fine and Gray [25]. Findings from all sensitivity analyses were consistent with those reported (data not shown).

\section{Results}

Tables 1 and 2 show participant characteristics stratified by cancer mortality and diabetes status, respectively. In this cohort of American Indians, there were $13.7 \%$ participants with IFG and $45.7 \%$ with diabetes at baseline. The prevalence of diabetes in this cohort was previously reported as $43 \%$ for men and $52 \%$ for women; a random 
sample $(n=311)$ of non-participants from this population showed a similar proportion of participants and non-participants with diabetes (40 and $38 \%$, respectively) [14]. During follow-up, 187 men and 243 women died from cancer, mainly from lung and prostate cancer in men and lung and breast cancer in women.

While confidence intervals are wide, due to small sample size, after multivariate adjustment for age, sex, BMI, education, drinking status, and smoking status (Table 3), the hazard ratio $(95 \% \mathrm{CI})$ for overall cancer mortality was $1.19(0.97-1.45)$ for those with diabetes compared to those without. The corresponding hazard ratios $(95 \% \mathrm{CI})$ for gastric, liver, and prostate cancers were 4.09 (1.42-11.79), 2.94 (1.17-7.40), and 3.11 (1.22-7.94), respectively. Similar results were observed in models that further adjusted for log-transformed urine arsenic and for number of packyears $(n=3,737)$, although the effect for overall cancer became significant in that analysis (HR 1.27; $95 \%$ CI 1.03-1.58), and a suggestive, but not statistically significant, association was observed for colorectal cancer (HR 1.92 ; $95 \%$ CI 0.92-4.00) (data not shown in tables). In the analysis of breast cancer, additional adjustment for parity and menopausal status did not affect our results. Similarly, adjustment for physical activity did not reveal significant changes in the risk of specific cancers, compared with model 3 .
When modeling the dose-response relationship between $\mathrm{HbA} 1 \mathrm{C}$ and cancer mortality, none of the associations were statistically significant (Fig. 1). For gastric cancer, the nonsignificant association was positive and fairly linear. For prostate cancer, the nonsignificant association was nonlinear. Total cancer was not associated with $\mathrm{HbA1C}$ (HR per IQR in HbA1c levels: 0.99; $95 \%$ CI 0.85, 1.15).

Results for HOMA-IR and cancer (Table 4) showed only a positive association between HOMA-IR values and liver cancer mortality (HR 4.70 per log unit; $95 \%$ CI 1.55-14.26). Unexpectedly, we also observed a negative association between HOMA-IR values and prostate cancer mortality. Similar findings were observed with plasma insulin (Table 4). HOMA-IR was not associated with total cancer mortality (HR per $\log$ unit of HOMA-IR was $0.92 ; 95 \%$ CI $0.73,1.18$ ).

\section{Discussion}

In this population-based cohort study with almost 20 years of follow-up, we found that baseline type 2 diabetes was associated with a borderline significant increase risk of overall cancer mortality among American Indians from Arizona, Oklahoma, and North/South Dakota. The association became significant in a subset of the population with information available on arsenic exposure, after adjustment

Table 1 Baseline characteristics of study participants overall and by cancer mortality status

\begin{tabular}{|c|c|c|c|c|}
\hline & $\begin{array}{l}\text { Overall } \\
(n=4,419)\end{array}$ & $\begin{array}{l}\text { Cancer deaths } \\
(n=430)\end{array}$ & $\begin{array}{l}\text { Non-cancer deaths } \\
\text { or alive }(n=3,989)\end{array}$ & $p$ value* \\
\hline Age (years) & $55.1(8.1)$ & $60.4(8.2)$ & $54.6(8.0)$ & $<0.01$ \\
\hline Men $(\%)$ & 40.6 & 43.5 & 40.3 & 0.21 \\
\hline Arizona $(\%)$ & 33.0 & 26.7 & 33.7 & $<0.01$ \\
\hline Oklahoma (\%) & 32.4 & 32.6 & 33.4 & 0.71 \\
\hline North/South Dakota (\%) & 33.6 & 40.7 & 32.9 & $<0.01$ \\
\hline$<$ High school $(\%)$ & 47.7 & 54.4 & 46.9 & $<0.01$ \\
\hline Current smoking $(\%)$ & 33.8 & 44.4 & 32.7 & $<0.01$ \\
\hline Former smoking (\%) & 33.9 & 31.4 & 34.1 & 0.25 \\
\hline Current drinking (\%) & 41.4 & 35.1 & 42.1 & $<0.01$ \\
\hline Obesity (BMI $\geq 30)(\%)$ & 50.9 & 46.3 & 51.3 & 0.05 \\
\hline Diabetes $(\%)^{* *}$ & 45.7 & 44.9 & 45.8 & 0.73 \\
\hline Impaired fasting glucose $(\%) * * *$ & 13.7 & 15.6 & 13.5 & 0.24 \\
\hline $\operatorname{HOMA-IR}(\%)^{\mathrm{a}}$ & $4.0(3.6)$ & $3.8(3.5)$ & $4.1(3.6)$ & 0.28 \\
\hline $\operatorname{HbA1C}(\%)^{\mathrm{b}}$ & $6.7(2.4)$ & $6.4(2.1)$ & $6.7(2.5)$ & 0.02 \\
\hline
\end{tabular}

Data in the table are percentages for categorical variables or means (standard deviations) for continuous variables

* Based on the Chi-square test for qualitative variables and analysis of the variance for quantitative variables

** Defined as a fasting plasma glucose level $\geq 126 \mathrm{mg} / \mathrm{dL}$

*** Defined as a fasting plasma glucose level of $110-125 \mathrm{mg} / \mathrm{dL}$

${ }^{a}$ Based on 2,400 participants without diabetes and with HOMA-IR available

b Based on 4,116 participants with this information available 
Table 2 Population characteristics by diabetes status

\begin{tabular}{|c|c|c|c|c|}
\hline & $\begin{array}{l}\text { Normal fasting glucose } \\
(n=1,795)\end{array}$ & $\begin{array}{l}\text { Impaired fasting glucose } \\
(n=606)^{*}\end{array}$ & Diabetes $(n=2,018)^{* *}$ & $p$ value*** \\
\hline Age (years) & $53.7(8.0)$ & $55.3(8.4)$ & $56.1(7.9)$ & 0.14 \\
\hline $\operatorname{Men}(\%)$ & 43.9 & 42.1 & 37.3 & $<0.01$ \\
\hline Arizona $(\%)$ & 19.2 & 26.9 & 47.2 & $<0.01$ \\
\hline Oklahoma (\%) & 38.9 & 36.1 & 27.6 & $<0.01$ \\
\hline North/South Dakota (\%) & 41.9 & 37.0 & 25.2 & $<0.01$ \\
\hline$<$ High school $(\%)$ & 41.2 & 45.5 & 54.1 & $<0.01$ \\
\hline Current smoking (\%) & 41.8 & 34.7 & 26.5 & $<0.01$ \\
\hline Former smoking (\%) & 29.9 & 33.3 & 37.6 & $<0.01$ \\
\hline Current drinking (\%) & 48.3 & 43.4 & 34.7 & $<0.01$ \\
\hline Obesity $(\mathrm{BMI} \geq 30)(\%)$ & 38.8 & 58.3 & 59.4 & $<0.01$ \\
\hline HOMA-IR $(\%)^{\mathrm{a}}$ & $3.4(2.9)$ & $6.0(4.5)$ & - & $<0.01$ \\
\hline $\operatorname{HbA1C}(\%)^{\mathrm{b}}$ & $5.1(0.6)$ & $5.4(0.7)$ & $8.6(2.4)$ & $<0.01$ \\
\hline
\end{tabular}

Data in the table are percentages (standard errors) for categorical variables or means (standard errors) for continuous variables

* Defined as a fasting plasma glucose level of $110-125 \mathrm{mg} / \mathrm{dL}$

** Defined as a fasting plasma glucose level $\geq 126 \mathrm{mg} / \mathrm{dL}$

*** Based on the Chi-square test for qualitative variables and analysis of the variance for quantitative variables

${ }^{a}$ Based on 2,400 participants without diabetes and with HOMA-IR available

b Based on 4,116 participants with this information available

Table 3 Hazard ratios (95\% confidence interval) for all-cause and site-specific cancer mortality by diabetes status $(n=4,419)$. Bolded values are statistically significant

\begin{tabular}{|c|c|c|c|c|}
\hline Type of cancer & Cases/non-cases & Model 1 & Model 2 & Model 3 \\
\hline Total cancer (ICD-9 codes 140-208) & $428 / 3,969$ & $1.14(0.94-1.39)$ & $1.16(0.95-1.41)$ & $1.20(0.98-1.47)$ \\
\hline Esophagus (ICD 9 code 150$)$ & $9 / 4,388$ & $0.56(0.13-2.33)$ & $0.61(0.14-2.65)$ & $0.65(0.15-2.82)$ \\
\hline Stomach (ICD 9 code 151) & $19 / 4,378$ & $4.00(1.42-11.30)$ & $3.90(1.37-11.09)$ & $4.20(1.45-12.13)$ \\
\hline Colon and rectum (ICD 9 codes $153-154)$ & $35 / 4,397$ & $1.72(0.87-3.37)$ & $1.65(0.83-3.28)$ & $1.77(0.88-3.54)$ \\
\hline Liver, intrahepatic bile ducts (ICD 9 code 155 ) & $24 / 4,373$ & $2.72(1.10-6.76)$ & $2.71(1.08-6.76)$ & $2.93(1.16-7.38)$ \\
\hline Gallbladder, extrahepatic bile ducts (ICD 9 code 156 ) & $13 / 4,384$ & $0.91(0.29-2.93)$ & $0.79(0.25-2.51)$ & $0.63(0.19-2.05)$ \\
\hline Pancreas (ICD 9 code 157$)$ & $27 / 4,397$ & $1.26(0.58-2.76)$ & $1.33(0.60-2.93)$ & $1.44(0.65-3.21)$ \\
\hline Trachea, bronchus, and lung (ICD 9 code 162) & $83 / 4,314$ & $0.62(0.38-1.02)$ & $0.70(0.42-1.16)$ & $0.72(0.43-1.21)$ \\
\hline Breast $(I C D 9 \text { code } 174)^{\mathrm{a}}$ & $26 / 2,587$ & $1.41(0.64-2.12)$ & $1.38(0.62-2.08)$ & $1.32(0.58-2.99)$ \\
\hline Prostate (ICD 9 code 185) & $20 / 1,764$ & $2.37(0.98-5.75)$ & $2.70(1.09-6.65)$ & $2.96(1.15-7.57)$ \\
\hline Kidney (ICD 9 code 189) & $30 / 4,367$ & $0.96(0.46-2.02)$ & $0.91(0.43-1.92)$ & $0.91(0.43-1.92)$ \\
\hline Lymphatic and hematopoietic tissue (ICD 9 codes 200-208) & $43 / 4,376$ & $0.89(0.48-1.66)$ & $0.86(0.46-1.61)$ & $1.20(0.98-1.47)$ \\
\hline
\end{tabular}

Model 1: adjusted for age and sex, stratified by center

Model 2: further adjusted for body mass index $\left(<25 ; \geq 25\right.$ and $\left.<30 ; \geq 25 \mathrm{~kg} / \mathrm{m}^{2}\right)$

Model 3: further adjusted for education, drinking status (never drinker/former drinker/light current drinker $(<4$ drinks/week)/moderate current drinkers (4-12 drinks/week)/heavy drinkers ( $>12$ drinks/week)) and smoking status (never, former, current)

${ }^{a}$ Model 2 for breast cancer further adjusts for menopausal status, and models 3 and 4 further adjust for reproductive factors: menopause (yes/no) and parity $(0,1-2,3-4, \geq 5)$

for this variable. Hyperglycemia, as measured by HbA1c, was also nonsignificantly associated with increased cancer risk. We found no clear association between baseline insulin resistance and overall cancer mortality, although HOMA-IR levels were positively associated with liver cancer and inversely associated with prostate cancer mortality.
The present study provides further evidence for increased risk of specific cancer mortality, including gastric and liver cancer, with baseline diabetes, although cautious interpretation is warranted, given the relatively small sample size. These findings are consistent with our a priori hypothesis based on reports conducted in Australia, East 
Gastric cancer

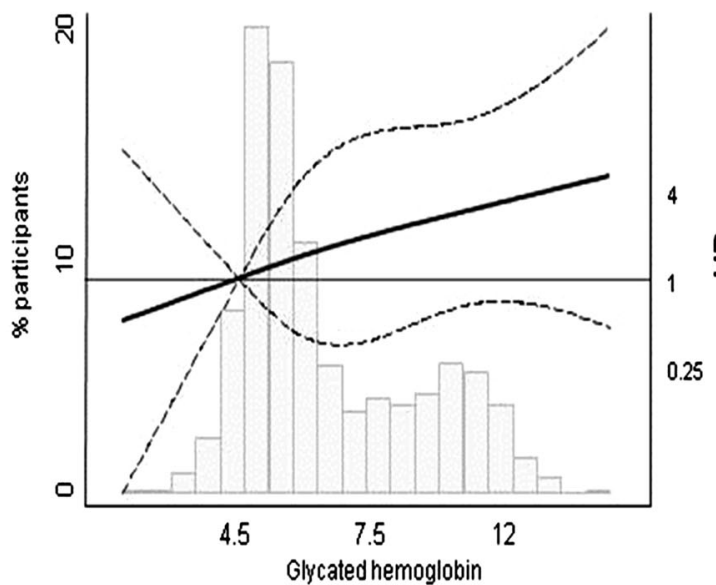

Liver cancer

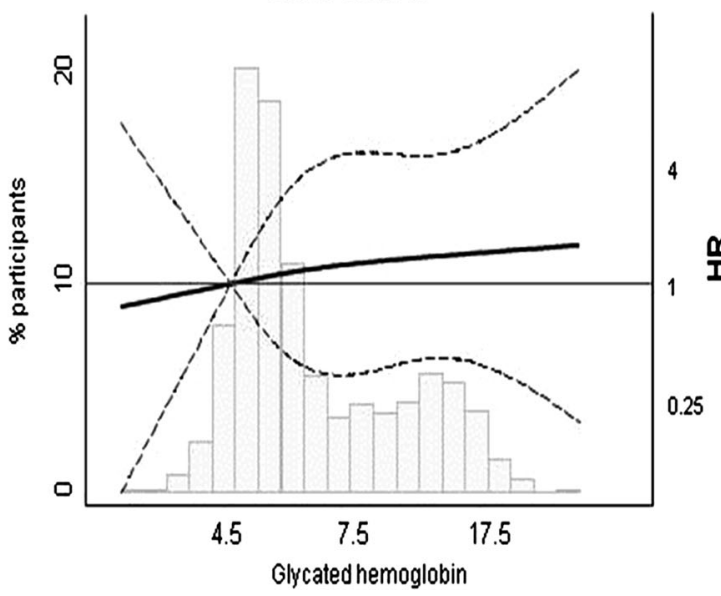

Colorectal cancer

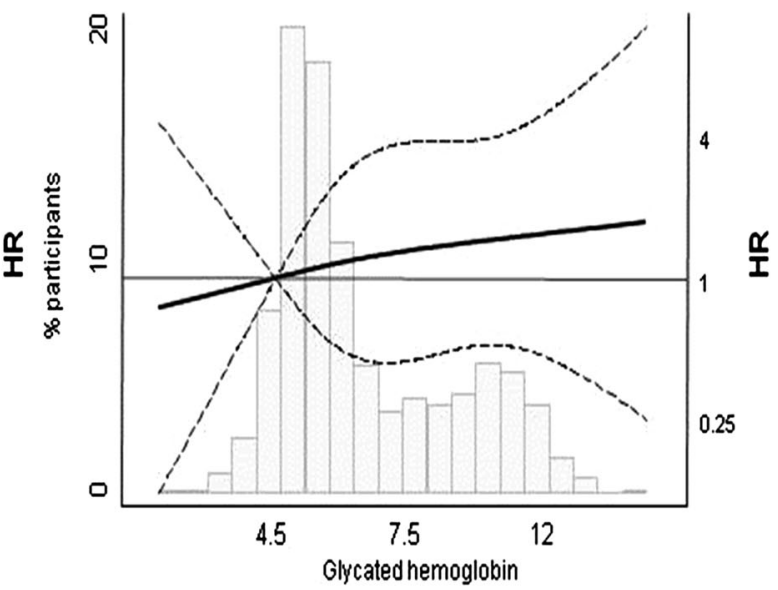

Prostate cancer

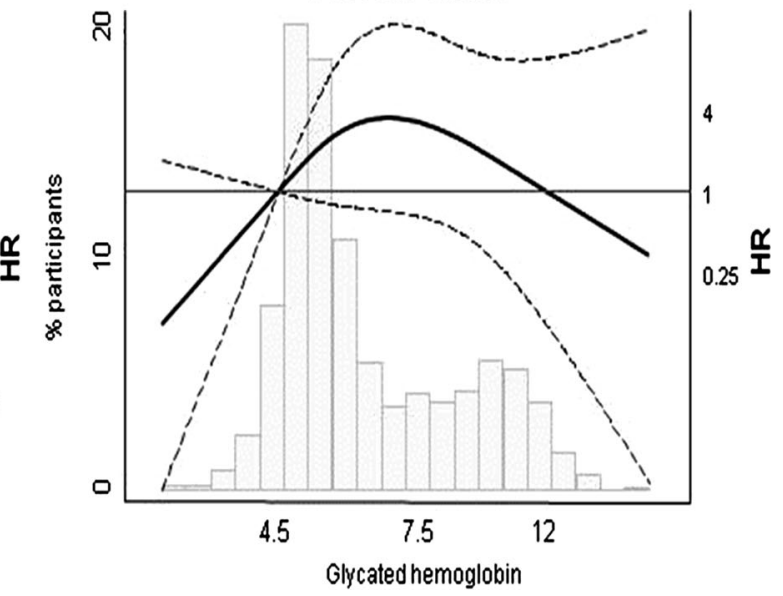

Fig. 1 Distribution of glycated hemoglobin $(\% \mathrm{HbA} 1 \mathrm{c})$ and hazard ratios for selected cancer mortality by $\% \mathrm{HbA} 1 \mathrm{c}$

Asia, North America, and Europe [26-30]. Also consistent with our a priori hypothesis, we found a nonsignificant, but increased mortality risk estimate for colorectal cancer.

Hyperglycemia may contribute to the initial mutagenic events initiating neoplasia, via an increase in reactive oxygen species [31]. Additionally, two subsequent independent mechanisms enhancing carcinogenesis could promote cancer development: (1) the increased availability of glucose coupled with the Warburg effect and (2) the availability of endogenous insulin and insulin-like growth factors (IGFs), which are increased before and during the early course of type II diabetes and have a synergistic effect on tumor growth. Interestingly, Laron dwarfism, a syndrome characterized by a lack of functional IGF-1 receptors, confers a marked reduction in cancer risk [32]. In epidemiologic studies, treatment with insulin $[33,34]$ or insulin secretagogues [35] has been associated with an increased risk of some cancers, including breast, colon, pancreas, and prostate. Also, agents that decrease insulin resistance and thus decrease insulin levels (metformin) have been associated with a decreased risk of stomach, liver, pancreatic, and colorectal cancers [36], although there is recent conflicting evidence [37]. It is unclear whether hyperglycemia could show effects for certain, specific cancers and not for others.

In our study, HbA1c, HOMA-IR, and plasma insulin per se were associated with an increased risk of liver cancer mortality among those without diabetes, a finding that is consistent with previous epidemiologic studies [38-40].

An extensive review of meta-analyses points out various weaknesses in previous studies associating specific cancers with diabetes, but finds the most robust evidence for breast, intrahepatic cholangiocarcinoma, colorectal, and endometrial cancers [41]. This is consistent with our findings, while allowing for potential overlap in the classification of hepatocellular versus cholangiocarcinoma. Interestingly, the Beckwith-Wiedemann syndrome, with known elevations of insulin and IGFs during the first years of life, is associated with very high incidence of cancer in childhood, especially hepatoblastoma and Wilm's tumor [42]. Another 
Table 4 Hazard ratios for site-specific cancer mortality among those without diabetes by insulin resistance (log HOMA-IR model) and log plasma insulin $(n=2,400)$. Bolded values are statistically significant

\begin{tabular}{|c|c|c|c|c|}
\hline Cancer & Cases/non-cases & & HOMA-IR HR (95\% CI) & Plasma insulin HR $(95 \% \mathrm{CI})$ \\
\hline \multirow[t]{3}{*}{ Stomach } & \multirow[t]{3}{*}{$5 / 2,395$} & Model 1 & $0.64(0.16-2.54)$ & $1.03(0.52-2.06)$ \\
\hline & & Model 2 & $0.33(0.06-1.91)$ & $0.94(0.42-2.08)$ \\
\hline & & Model 3 & $0.29(0.04-2.11)$ & $0.95(0.42-2.13)$ \\
\hline \multirow[t]{3}{*}{ Liver, intrahepatic bile ducts } & \multirow[t]{3}{*}{$7 / 2,393$} & Model 1 & $4.68(1.57-13.98)$ & $2.51(1.54-4.11)$ \\
\hline & & Model 2 & $4.72(1.47-15.13)$ & $2.70(1.62-2.26)$ \\
\hline & & Model 3 & $4.70(1.55-14.26)$ & $2.71(1.62-3.29)$ \\
\hline \multirow[t]{3}{*}{ Prostate } & \multirow[t]{3}{*}{$9 / 2,391$} & Model 1 & $0.34(0.13-0.83)$ & $0.42(0.18-0.97)$ \\
\hline & & Model 2 & $0.23(0.07-0.75)$ & $0.51(0.22-1.18)$ \\
\hline & & Model 3 & $0.25(0.07-0.88)$ & $0.82(0.24-2.00)$ \\
\hline \multirow[t]{3}{*}{ Colon and rectum } & \multirow[t]{3}{*}{$35 / 2,384$} & Model 1 & $0.94(0.44-1.99)$ & $1.27(0.79-2.03)$ \\
\hline & & Model 2 & $0.76(0.31-1.92)$ & $1.17(0.68-2.03)$ \\
\hline & & Model 3 & $0.81(0.32-2.08)$ & $1.22(0.71-2.11)$ \\
\hline
\end{tabular}

Model 1: adjusted for age and sex, stratified by center

Model 2: further adjusted for body mass index $\left(<25 ; \geq 25\right.$ and $\left.<30 ; \geq 25 \mathrm{~kg} / \mathrm{m}^{2}\right)$

Model 3: further adjusted for education, drinking status (never, former, current), smoking status (never, former, current)

mechanism that may increase liver cancer risk of those with diabetes is the impaired immune function that potentially interferes with neoplastic surveillance and encourages chronic viral infection, such as hepatitis B and hepatitis C.

The association between diabetes and gastric cancer mortality in our study is consistent with findings from several meta-analyses published between 2011 and 2013 showing an increased risk of gastric cancer in individuals with diabetes. A recent review has considered the multiple interacting factors that may play a role in this association [43]. These include possibly higher infection rates or prevalence of Helicobacter pylori infection, potentially increased salt intake, or increased detection rates among those with diabetes requiring routine medical care for a chronic condition.

There appear to be differential effects of elevated levels of glucose and insulin during the prodromal/early stages of diabetes on the development of prostate cancer, compared with the influence of fully developed diabetes on the risk of prostate cancer mortality [44]. Evidence from a metaanalysis [45] and two large cohort studies [46, 47] showed lower prostate cancer incidence in individuals with longstanding diabetes compared to those without diabetes. The present study found that increased levels of insulin and insulin resistance (typical of subclinical diabetes) among those without diabetes were associated with lower risk of prostate cancer death. After the development of prostate cancer, however, the presence of diabetes seems to confer an increased risk of prostate cancer death. A recently published meta-analysis found an increased risk of prostate cancer mortality among those with diabetes [48]; however, a large collaborative study including a total of 2,217 prostate cancer deaths [49] found a nonsignificant decreased risk of mortality in individuals with diabetes. The present study provides further evidence for diabetes as a risk factor for prostate cancer death. Overall, the relationship of diabetes and its physiologic changes with prostate cancer incidence and mortality is complex [50, 51]. Future research is needed to more accurately consider the time course of these physiologic changes, as well as the social and medical influences on the relationship between prostate cancer development and associated mortality.

Interpretation of this epidemiologic evidence should be undertaken with caution considering the multiple and possibly countervailing influences of factors difficult to track over the relevant exposure period. These could include the direct effects of hyperglycemia as well as secondary physiologic responses to hyperglycemia (e.g., insulin and the effects of the insulin-like growth factor system) and treatment of diabetes. Although we adjusted for obesity, there could also be effects of obesity per se. The evaluation of the role of obesity on cancer is very complex, especially in a study that evaluates cancer mortality instead of cancer incidence. Indeed, at baseline, participants who later died of cancer were less likely to be obese compared to those without a subsequent cancer death. It is well known that the obesity of those with diabetes tends to ameliorate with advancing age; insulin levels decline with time as beta-cell function fails $[52,53]$. There is also evidence that the influence of the IGF system declines with age in a parallel fashion to that of insulin 
[54]. It is challenging to confidently model or adjust for these multiple factors and their possible interactions. There are a number of effects, by which diabetes could increase the likelihood of death among those who have already developed cancer, such as increased cardiovascular complications and increased susceptibility to infections.

The Strong Heart Study was initially designed to study the prevalence of known or suspected cardiovascular disease risk factors in American Indians and to assess their influence on cardiovascular morbidity and mortality (http://stron gheart.ouhsc.edu/). However, the long follow-up of Strong Heart Study participants has allowed us to secondarily evaluate the influence of some of these risk factors on cancer mortality. For this reason, we do not have information on certain confounders that are of obvious interest (e.g., family history of the studied cancers, stage at diagnosis, treatment, and some environmental exposures), making residual confounding likely. It was not possible to evaluate for potential confounding due to aspirin or non-steroidal anti-inflammatory agents because the only information available was on sporadic use. Since the analysis is based on cancer mortality, conclusions may have also been biased by differences in healthcare utilization, or access to more specialized services by those with diabetes, compared to those without diabetes. Finally, we lack incidence data, and particularly among tumors with high survival (e.g., breast or colorectal), the power to detect significant associations is limited by the small number of deaths from those cancers.

The strengths of this study include the prospective analysis, the availability of relevant covariates (including arsenic, an established carcinogen that was present in drinking water at levels above $10 \mu \mathrm{g} / \mathrm{L}$, the current US EPA standard) [55] to adjust for confounding, and a population with a unique genetic background.

In a population with a high prevalence of diabetes and obesity and with unique environmental exposures, our data provide additional evidence of heightened risk of cancer mortality associated with diabetes and confirmation of increased risk of mortality due to stomach and liver cancers. Additional research is needed to evaluate the role of diabetes and obesity on cancer incidence in American Indian communities as well as the importance of diabetes prevention and control in reducing the burden of cancer incidence and mortality in the study population.

Acknowledgments We thank the SHS participants, Indian Health Service facilities, and participating tribal communities for their extraordinary cooperation and involvement, which has contributed to the success of the Strong Heart Study. The views expressed in this paper are those of the authors and do not necessarily reflect those of the Indian Health Service.

Funding This work was supported by cooperative agreement Grants, R01HL090863 and R01ES021367, from the National Heart, Lung, and Blood Institute and the National Institute of Environmental
Health Sciences, Bethesda, MD. Navas-Acien, Ana: R01ES021367, National Institute of Environmental Health Sciences, Bethesda; R01HL090863, National Heart, Lung, and Blood Institute, Bethesda, MD. All other authors: U01-HL65520, U01-HL41642, U01HL41652, U01-HL41654, U01-HL65521, RO1HL109315, R01HL109284, RO1HL109319, National Heart, Lung, and Blood Institute, Bethesda, MD.

Author contributions LGB designed study, researched data, and wrote manuscript. EGE conducted statistical analysis and wrote manuscript. J.L.Y., F.Y., Y.Z., E.T.L., B.V.H., T.K.W., E.R.R., and J.G.U. supervised data collection and reviewed/edited manuscript. J.H.F. and D.A.R. reviewed/edited manuscript. ANA supervised statistical analysis and reviewed/edited manuscript.

\section{Compliance with ethical standards}

Conflict of interest None of the authors have any conflicts of interest to report.

Open Access This article is distributed under the terms of the Creative Commons Attribution 4.0 International License (http://crea tivecommons.org/licenses/by/4.0/), which permits unrestricted use, distribution, and reproduction in any medium, provided you give appropriate credit to the original author(s) and the source, provide a link to the Creative Commons license, and indicate if changes were made.

\section{References}

1. Yuhara H, Steinmaus C, Cohen SE, Corley DA, Tei Y, Buffler PA (2011) Is diabetes mellitus an independent risk factor for colon cancer and rectal cancer? Am J Gastroenterol 106:1911-1921

2. Boyle P, Boniol M, Koechlin A, Robertson C, Valentini F, Coppens $\mathrm{K}$ et al (2012) Diabetes and breast cancer risk: a metaanalysis. Br J Cancer 107:1608-1617

3. Giovannucci E, Harlan DM, Archer MC, Bergenstal RM, Gapstur SM, Habel LA et al (2010) Diabetes and cancer: a consensus report. Diabetes Care 33:1674-1685

4. Rosato V, Tavani A, Bosetti C, Pelucchi C, Talamini R, Polesel J et al (2011) Metabolic syndrome and pancreatic cancer risk: a case-control study in Italy and meta-analysis. Metabolism 60:1372-1378

5. Faulds MH, Dahlman-Wright K (2012) Metabolic diseases and cancer risk. Curr Opin Oncol 24:58-61

6. Noto H, Tsujimoto T, Sasazuki T, Noda M (2011) Significantly increased risk of cancer in patients with diabetes mellitus: a systematic review and meta-analysis. Endocr Pract 17:616-628

7. Dang CV (2012) Links between metabolism and cancer. Genes Dev 26:877-890

8. Santra A, Kumar R, Sharma P, Bal C, Kumar A, Julka PK et al (2012) F-18 FDG PET-CT in patients with recurrent glioma: comparison with contrast enhanced MRI. Eur J Radiol $81: 508-513$

9. Barros LF, San Martín A, Sotelo-Hitschfeld T, Lerchundi R, Fernández-Moncada I, Ruminot I et al (2013) Small is fast: astrocytic glucose and lactate metabolism at cellular resolution. Front Cell Neurosci 7:27

10. Chen W, Wang S, Tian T, Bai J, Hu Z, Xu Y et al (2009) Phenotypes and genotypes of insulin-like growth factor 1, IGFbinding protein-3 and cancer risk: evidence from 96 studies. Eur J Hum Genet 17:1668-1675

11. Chen J (2011) Multiple signal pathways in obesity-associated cancer. Obes Rev 12:1063-1070 
12. White MC, Espey DK, Swan J, Wiggins CL, Eheman C, Kaur JS (2014) Disparities in cancer mortality and incidence among American Indians and Alaska Natives in the United States. Am J Public Health 104(Suppl 3):S377-S387

13. US Department of Health and Human Services (2012) Health, United States, 2011: with special feature on socioeconomic status and health. National Center for Health Statistics, Hyattsville

14. Lee ET, Howard BV, Savage PJ, Cowan LD, Fabsitz RR, Oopik AJ et al (1995) Diabetes and impaired glucose tolerance in three American Indian populations aged 45-74 years. The Strong Heart Study. Diabetes Care 18:599-610

15. Centers for Disease Control and Prevention (CDC) (2003) Diabetes prevalence among American Indians and Alaska Natives and the overall population-United States, 1994-2002. MMWR Morb Mortal Wkly Rep 52:702-704

16. Valway S, Freeman W, Kaufman S, Welty T, Helgerson SD, Gohdes D (1993) Prevalence of diagnosed diabetes among American Indians and Alaska Natives, 1987. Estimates from a national outpatient data base. Diabetes Care 1993(16):271-276

17. Lu W, Resnick HE, Jain AK, Adams-Campbell LL, Jablonski KA, Gottlieb AM et al (2003) Effects of isolated post-challenge hyperglycemia on mortality in American Indians: the Strong Heart Study. Ann Epidemiol 13:182-188

18. Zhang Y, Lee ET, Howard BV, Best LG, Umans JG, Yeh J et al (2013) Insulin resistance, incident cardiovascular diseases, and decreased kidney function among nondiabetic American Indians: the Strong Heart Study. Diabetes Care 36:3195-3200

19. De Marco M, de Simone G, Roman MJ, Chinali M, Lee ET, Calhoun D et al (2011) Cardiac geometry and function in diabetic or prediabetic adolescents and young adults: the Strong Heart Study. Diabetes Care 34:2300-2305

20. Lu WQ, Resnick HE, Jablonski KA, Jain AK, Jones KL, Robbins DC et al (2004) Effects of glycaemic control on cardiovascular disease in diabetic American Indians: the Strong Heart Study. Diabet Med 21:311-317

21. Devereux RB, Roman MJ, Paranicas M, Lee ET, Welty TK, Fabsitz RR et al (2001) A population-based assessment of left ventricular systolic dysfunction in middle-aged and older adults: the Strong Heart Study. Am Heart J 141:439-446

22. Lu W, Jablonski KA, Resnick HE, Jain AK, Jones KL, Gottlieb AM et al (2003) Alcohol intake and glycemia in American Indians: the Strong Heart Study. Metabolism 52:129-135

23. García-Esquinas E, Pollán M, Umans JG, Francesconi KA, Goessler W, Guallar E et al (2013) Arsenic exposure and cancer mortality in a US-based prospective cohort: the strong heart study. Cancer Epidemiol Biomark Prev 22:1944-1953

24. Gribble MO, Howard BV, Umans JG, Shara NM, Francesconi KA, Goessler W et al (2012) Arsenic exposure, diabetes prevalence, and diabetes control in the Strong Heart Study. Am J Epidemiol 176:865-874

25. Fine JP, Gray RJ (1999) A proportional hazards model for the subdistribution of a competing risk. J Am Stat Assoc 94:496-509

26. Tian T, Zhang LQ, Ma XH, Zhou JN, Shen J (2012) Diabetes mellitus and incidence and mortality of gastric cancer: a metaanalysis. Exp Clin Endocrinol Diabetes 120:217-223

27. Huang W, Ren H, Ben Q, Cai Q, Zhu W, Li Z (2012) Risk of esophageal cancer in diabetes mellitus: a meta-analysis of observational studies. Cancer Causes Control 23:263-272

28. Wang C, Wang X, Gong G, Ben Q, Qiu W, Chen Y et al (2012) Increased risk of hepatocellular carcinoma in patients with diabetes mellitus: a systematic review and meta-analysis of cohort studies. Int J Cancer 130:1639-1648

29. Yang WS, Va P, Bray F, Gao S, Gao J, Li HL et al (2011) The role of pre-existing diabetes mellitus on hepatocellular carcinoma occurrence and prognosis: a meta-analysis of prospective cohort studies. PLoS ONE 6:e27326
30. Yoon JM, Son KY, Eom CS, Durrance D, Park SM (2013) Preexisting diabetes mellitus increases the risk of gastric cancer: a meta-analysis. World J Gastroenterol 19:936-945

31. Arcidiacono B, Iiritano S, Nocera A, Possidente K, Nevolo MT, Ventura V et al (2012) Insulin resistance and cancer risk: an overview of the pathogenetic mechanisms. Exp Diabetes Res 2012:789174

32. Steuerman R, Shevah O, Laron Z (2011) Congenital IGF1 deficiency tends to confer protection against post-natal development of malignancies. Eur J Endocrinol 164:485-489

33. Hemkens LG, Grouven U, Bender R, Günster C, Gutschmidt S, Selke GW et al (2009) Risk of malignancies in patients with diabetes treated with human insulin or insulin analogues: a cohort study. Diabetologia 52:1732-1744

34. Mannucci E (2012) Insulin therapy and cancer in type 2 diabetes. ISRN Endocrinol 2012:240634

35. Currie CJ, Poole CD, Gale EA (2009) The influence of glucoselowering therapies on cancer risk in type 2 diabetes. Diabetologia 52:1766-1777

36. Franciosi M, Lucisano G, Lapice E, Strippoli GF, Pellegrini F, Nicolucci A (2013) Metformin therapy and risk of cancer in patients with type 2 diabetes: systematic review. PLoS ONE 8:e71583

37. Tsilidis KK, Capothanassi D, Allen NE, Rizos EC, Lopez DS, van Veldhoven K et al (2014) Metformin does not affect cancer risk: a cohort study in the U.K. Clinical Practice Research Datalink analyzed like an intention-to-treat trial. Diabetes Care 37:2522-2532

38. Capasso I, Esposito E, Pentimalli F, Montella M, Crispo A, Maurea $\mathrm{N}$ et al (2013) Homeostasis model assessment to detect insulin resistance and identify patients at high risk of breast cancer development: national cancer institute of Naples experience. J Exp Clin Cancer Res. 32:14

39. Khattab MA, Eslam M, Mousa YI, Ela-adawy N, Fathy S, Shatat $M$ et al (2012) Association between metabolic abnormalities and hepatitis C-related hepatocellular carcinoma. Ann Hepatol 11:487-494

40. Sieri S, Muti P, Claudia A, Berrino F, Pala V, Grioni S et al (2012) Prospective study on the role of glucose metabolism in breast cancer occurrence. Int J Cancer 130:921-929

41. Tsilidis KK, Kasimis JC, Lopez DS, Ntzani EE, Ioannidis JP (2015) Type 2 diabetes and cancer: umbrella review of metaanalyses of observational studies. BMJ 350:g7607

42. Choufani S, Shuman C, Weksberg R (2010) Beckwith-Wiedemann syndrome. Am J Med Genet C Semin Med Genet $154 \mathrm{C}: 343-354$

43. Tseng CH, Tseng FH (2014) Diabetes and gastric cancer: the potential links. World J Gastroenterol 20:1701-1711

44. Onitilo AA, Engel JM, Glurich I, Stankowski RV, Williams GM, Doi SA (2012) Diabetes and cancer I: risk, survival, and implications for screening. Cancer Causes Control 23:967-981

45. Kasper JS, Giovannucci E (2006) A meta-analysis of diabetes mellitus and the risk of prostate cancer. Cancer Epidemiol Biomark Prev 15:2056-2062

46. Kasper JS, Liu Y, Giovannucci E (2009) Diabetes mellitus and risk of prostate cancer in the health professionals follow-up study. Int J Cancer 124:1398-1403

47. Carstensen B, Witte DR, Friis S (2012) Cancer occurrence in Danish diabetic patients: duration and insulin effects. Diabetologia 55:948-958

48. Cai H, Xu Z, Xu T, Yu B, Zou Q (2015) Diabetes mellitus is associated with elevated risk of mortality amongst patients with prostate cancer: a meta-analysis of 11 cohort studies. Diabetes Metab Res Rev 31:336-343

49. Collaboration Emerging Risk Factors, Seshasai SR, Kaptoge S, Thompson A, DiAngelantonio E, Gao P, Sarwar N et al (2011) 
Diabetes mellitus, fasting glucose, and risk of cause-specific death. N Engl J Med 364:829-841

50. Ma J, Li H, Giovannucci E, Mucci L, Qiu W, Nguyen PL, Gaziano JM et al (2008) Prediagnostic body-mass index, plasma C-peptide concentration, and prostate cancer-specific mortality in men with prostate cancer: a long-term survival analysis. Lancet Oncol 9:1039-1047

51. Hammarsten J, Högstedt B (2005) Hyperinsulinaemia: a prospective risk factor for lethal clinical prostate cancer. Eur $\mathrm{J}$ Cancer 41:2887-2895

52. Xiang AH, Wang C, Peters RK, Trigo E, Kjos SL, Buchanan TA (2006) Coordinate changes in plasma glucose and pancreatic beta-cell function in Latino women at high risk for type 2 diabetes. Diabetes 55:1074-1079
53. Gerich JE (2003) Contributions of insulin-resistance and insulinsecretory defects to the pathogenesis of type 2 diabetes mellitus. Mayo Clin Proc 78:447-456

54. Sittadjody S, Ilangovan R, Thangasamy T, Vignesh RC, Veni S, Bertoni AG et al (2012) Age-related changes in serum levels of insulin-like growth factor-II and its binding proteins correlate with calcaneal bone mineral density among post-menopausal South-Indian women. Clin Chim Acta 414:281-288

55. Navas-Acien A, Umans JG, Howard BV, Goessler W, Francesconi KA, Crainiceanu CM et al (2009) Urine arsenic concentrations and species excretion patterns in American Indian communities over a 10-year period: the Strong Heart Study. Environ Health Perspect 117:1428-1433 